\title{
Commentary on Furnham's Culture Shock, Berry's Acculturation Theory, and Marsella and Yamada's Indigenous Psychopathology: Being a Call to Action for Pacific Rim Psychology
}

\author{
James H. Liu \\ Victoria University of Wellington, Wellington, New Zealand
}

\begin{abstract}
$T^{n}$ he three articles in this special edition of the Journal of Pacific Rim Psychology encompass a range of approaches within cross-cultural psychology. Adrian Furnham's (2011) culture shock shows how academic psychology can be applied to, and helps to inform a popular concept. John Berry's (2011) acculturation theory demonstrates how focused theory and empirical data can align with a national agenda. Anthony J. Marsella and Ann Marie Yamada's (2011) socioconstructionist critique of mainstream clinical psychology and psychiatric practices illustrate how epistemology and indigenous psychology can challenge institutional practices. They are united in rejecting a culture-blind psychology of the mainstream. They differ by referencing largely separate but nonetheless complementary literatures on cultures of relevance to the Pacific Rim region. Taken together, these three articles combine meaningfully to illustrate how Pacific Rim psychology might benefit from having (1) a definition of itself with Hawaii and the Pacific Island Nations as the centre and hub for the broader Pacific Rim that includes East Asia and the Western American seaboard; (2) a focus on action, particularly action research and its cyclical communication process of planning, action, evaluation and feedback; and (3) an interdisciplinary orientation where interconnectedness with such institutions as mass media, government, and clinical and psychiatric practices, as well as within psychology itself, underpin and inform research practice and policy.
\end{abstract}

Keywords: culture shock, acculturation, psycho-pathology, culture, pacific rim psychology, action research, indigenous psychology

\section{Context}

The three articles in this special edition of the Journal of Pacific Rim Psychology encompass a range of approaches within cross-cultural psychology. The article by Adrian Furnham (2011) on culture shock shows how academic psychology can be applied to a popular concept. The second article by John Berry (2011) presents a summary of the author's eco-cultural framework and his integration theory of acculturation. The third article by Anthony Marsella and Anne Marie
Yamada (2011) provides a sociocultural constructionist critique of mainstream practices in clinical psychology. While taking different approaches, the three are united by a commitment to culture as a subject of social scientific analysis. Marsella and Yamada (2011) provide a definition of culture as 'shared learned behaviour and meanings that are socially transmitted for purposes of adjustment and adaptation ... represented externally in artefacts ... represented internally by values, attitudes, beliefs. ... and notions of personhood' (p. 105). The focus of this commentary will be to consider some of 
the major points of emphasis developed by the three authors, analyse where they overlap and where they depart from one another and provide a forwardlooking statement of what might be some strengths and weaknesses of the cross-cultural approach that may be of utility in developing a cultural psychology for the Pacific Rim.

\section{Adrian Furnham's Culture Shock}

The opening article by Furnham (2011) observes that while the term culture shock 'may have originated in the academic literature it very quickly took root in the popular imagination. The popular media has been full of references to culture shock for 50 years' (2011, p. 87). Such is the popularity of the term that a Google ${ }^{\mathrm{TM}}$ search yielded 97 million hits, with some of top ranked items including practical guides for immigration from government and commercial agencies, sites for international exchange students, a children's health organisation and a radio program. Furnham describes six aspects of it (based on Oberg's classic, 1960, definition), including psychological strain; a sense of loss and feelings of deprivation; being rejected or rejecting; confusion; and feelings of surprise, anxiety, indignation, and impotence. Furnham's book Culture Shock has attracted more than 700 academic references and is the most cited of this prolific author's work. This reaffirms what culture-oriented psychologists already know: in today's globalising world, adapting to different cultures is important and marketable to ordinary people and to organisations in both private and not-for-profit sectors.

Furnham (2011) attributes the concept's resonance with people and groups to the fact that it provide[s] 'some theoretical framework through which to understand the phenomenon', that it 'include[s] salient literature from many disciplines' and that it focuses upon 'practical implications' (p. 93). With further regard to connectivity, he identifies three further stakeholder groups as invested audiences for the work: international students, migrants and refugees. This is a powerful statement and identifies the good reasons for the international standing of his work.

The article is richly descriptive about mental health issues. It contains several useful taxonomies about phenomena related to culture shock and is full of references to a wide variety of authors providing numerous recommendations about how to identify and deal with different aspects of culture shock. Perhaps the most substantial section deals with international students' experiences, where 'much of this research suggests that many students feel classic alienation especially feelings of powerlessness, meaninglessness, and social estrangement while being surrounded by the 'superficial pleasantries' of their hosts' (p. 89). Rich nuggets of wisdom about easing the difficulty of cross-cultural adjustment abound, providing the reader with a primer on how to manage culture shock from the perspective of both educational institutions and individuals. Advice follows for such common ailments as homesickness and how educational institutions can help foreign students adapt to problems of crossing cultural boundaries. The writing is very accessible and engages with issues at the coalface of education experiences for international students. It serves as a practically organised and useful guide on how to deal with culture shock. The practical review provides a useful complement to a more traditional scholarly presentation in the same area by Ward (2001); her ABC taxonomy of reactions to acculturation - with $\mathrm{A}$ being affect (indexed by such measures as subjective wellbeing or lack of depression), B being behaviour (culture learning to survive in daily life), and $\mathrm{C}$ being cognition (including beliefs and social identities) - provides a systematic structuring framework for research in this area.

\section{John Berry's Acculturation Theory and Eco-cultural Framework}

John Berry's (2011) approach is different from Furnham's. He has a particular theory and he pushes this theory as hard as possible (for a critique of this, see Rudmin, 2006). The eco-cultural framework that he presents is 'a kind of map that lays out the categories of variables that need to be examined in studies seeking to understand human behavioural diversity, both in their local contexts and comparatively' (p. 96). The map provides academics with a system to navigate their research between universalism ('basic psychological processes are shared, species common characteristics' p. 96) and particularistic behaviours ('behaviour is considered to be differentially developed and expressed in response to ecological, socio-political and cultural contexts' p. 96). Within this framework,

the issue of differences need not be seen as one of deficiency or superiority. Psychological differences can be viewed as culturally adaptive expressions of underlying psychological universals that are guided by differential social and cultural contexts ... The basic idea is that the more differentiated is a person's psychological and social life, the better able they are to engage in intercultural and acculturation processes, and the more likely they are to have more positive outcomes. (p. 97)

Given that 'no society is made up of people having one culture, one language, and one identity', Berry moves on to theorise about acculturation, which is defined as 'the process of cultural and psychological change following contact between cultural groups and their individual members' (p. 97) from this eco-cultural frame. Foregrounding the longer-term personal and organisational management of culture shock, Berry argues that across cultures, individuals of different cultural backgrounds need to share some basic psychological features (commonalities) to interact with and adapt to one another in an accommodative manner, but at the same time maintain elements of their different heritage cultures. At the societal level, he describes two prevailing 
models for dealing with cultural differences, the melting pot (where a dominant group holds the centre and other groups remain on the margins unless they are assimilated within the dominant group) and the multicultural model, where there is a national framework of institutions that accommodates the needs and interests of numerous cultural groups and incorporates them pluralistically within the national framework. 'In such complex plural societies, there is no assumption that some groups should assimilate or become absorbed into another group. Hence, intercultural relations and change are not viewed as unidirectional, but as mutual and reciprocal' (p. 98).

This is the conception that has informed the multicultural vision in Canada' (Berry's homeland, p. 98, and part of our Pacific region). At the societal level, there needs to be a commitment to both heritage culture maintenance and equitable participation and incorporation of minority cultural groups into the larger society.

At the individual level, Berry and colleagues (particularly Berry, Phinney, Sam, \& Vedder, 2006) have found that an integration strategy towards acculturation where 'there was a positive attitude toward integration, positive identities with both cultural groups [heritage and larger society], knowledge and use of both languages, and friendships with members of both cultures' (p. 100) was both most preferred among ethno-cultural migrant youth and produced the best adaptation outcomes. Integrative youth also reported experiencing the least discrimination, whereas marginalised youth (engaged neither with their heritage culture nor the larger society) reported the most discrimination and the worst adaptation outcomes. Assimilation (favouring the larger society) and separation (favouring the heritage culture) strategies yielded intermediate adaptation outcomes.

As a consequence, Berry concludes that

Public policies that encourage and support balanced relationships and competencies in intercultural situations are thus superior to other arrangements ... These studies show that when individuals have a differentiated social network and are more differentiated psychologically, their wellbeing is superior to when they have limited (one culture or another) or no social engagements. (p. 101)

Berry's recommendation is more parsimonious than the previous article, a parsimony that is possibly purchased at the expense of 'how' integration can, in everyday terms, be achieved. This is a common enough dilemma, but it also signals perhaps that the key is to integrate the two models. An integration could occur over time, as individuals deal with culture shock across different domains and attempt to make sense of this in different ways (e.g., by compartmentalising their lives or by attempting to hybridise their behaviours or cognitions in the $\mathrm{ABC}$ taxonomy). It could be attempted across space, as we consider how integration is maintained in different social spaces (see Liu \& Sibley, 2004) and how different spaces serve different adaptive and normative functions.

That need for integration becomes stronger once we consider the final article, which focuses on wider intercultural interactions (e.g., historically, including the history of psychology, and their consequences, for example, for wellbeing and health for everyone who has encounters with other cultures and their systems of belief). At its worst, of course, extreme forms of culture shock might require clinical attention and intervention.

\section{Anthony Marsella and Ann Marie Yamada's Culture-Bound Psychopathology}

The third article, by Anthony Marsella and Ann Marie Yamada (2011), provides a historical overview of the field of clinical psychopathology.

In spite of the broad endorsement of the socio-cultural perspective across the decades, including by support from some of psychiatry's most famous figures, the socio-cultural perspective was widely dismissed by many others in psychiatry, who were committed to reductionist approaches that located the causes, manifestations, and cures of mental disorders in the brain and nervous system. (p. 104)

According to Marsella and Yamada (2011), it was not until the 1980s that cultural approaches to psychiatry gained widespread acceptance. They argue for the necessity of recognising that:

Western mental health professions, and sciences are "cultural constructions". As such, they must be seen as relative to the historical, linguistic, and socio-political influence of Western cultural traditions, and as such, they should not be considered as 'objective', but rather representations of cultural knowledge and practice. (p. 106)

They note that it is not until its very last pages that latest clinical diagnosis manual, the DSM-IV-TR (American Psychological Association, 2000) offers a series of criteria for identifying 'culture-bound syndromes'. This then is an argument for greater cultural competence within psychology itself.

With respect to that cultural competence, Marsella and Yamada (2011) provide an extensive analysis and description of culture-bound syndromes, focusing on Hawaiian people.

The Native Hawaiian culture considers all of its people to be embedded within a complex ecology of relationships among gods, nature, and family, and person ... Harmony (Lokahi) across these elements occurs as long as a person meets his/her individual, familial, environmental, and spiritual responsibilities. The cultural system is based on an ethos of preserving the social fabric of the group ... Within this framework, health and illness are considered to be a function of those forces that serve to either promote or to destroy harmony. (p. 107)

They provide illustrations of how emotions and actions take their meaning in terms of their impact on the fabric of social and spiritual relations, and how both social and spiritual actions can be taken to tear or repair the fabric. 
'Thus, the Native Hawaiian worldview encompasses a complex system that is rooted in the interaction of body, mind, and spirit. It is directly tied to pro-social human relations and pro-spiritual relations' (p. 109). Culture thus determines patterns of stressors, parameters of coping, basic personality patterns, language-based mediators of and responses to experience, and standards of and ways of classifying normality and deviance.

The authors argue passionately for a holistic view that:

Mental health is not only about biology and psychology, but also about education, economics, social structure, religion, and politics. There can be no mental health where there is powerlessness, because powerlessness breeds despair; there can be no mental health where there is poverty because poverty breeds hopelessness; there can be no mental health where there is inequality, because inequality breeds anger and resentment; there can be no mental health where there is racism because racism breeds low self-esteem and selfdenigration; and lastly, there can be no mental health where there is cultural disintegration and destruction, because cultural disintegration and destruction breed confusion and despair. (Marsella \& Yamada, 2000, as cited in Marsella \& Yamada, 2011, p. 109-110)

They call into question the ethnocentrism embedded within the science of psychiatric epidemiology, noting 'numerous issues involved in the assessment and diagnosis of mental illness across cultures' (p. 110) that make valid data collection for comparative study a difficult task. They illustrate this with:

historical, conceptual, and empirical studies that document the fact that schizophrenic disorders vary considerably across cultural boundaries and that the source of this may be both actual and may reside in the very conceptualization of schizophrenia replete with all its excess definitions, meanings, patterns, and treatment responses. (p. 111)

This is an argument for greater interdisciplinarity. The analysis is strong on criticism of the entrenched power structures around the diagnosis of mental illness in the United States (the focus of attention). It is a call for greater cultural competence in science and practice, not only in terms of awareness and knowledge, but also in terms of passion. In terms of the necessity for such competencies, the article complements the experiences of other Polynesian peoples in the Pacific Rim, including $\mathrm{T}$ ngata Whenua in Aotearoa/New Zealand. M ori peoples have also experienced adverse effects from colonisation. Not only have they challenged the hegemony of diagnostic categories in the DSM-IV, they have also moved in the direction of providing holistic models of mental health and mental health care (see Durie, 1997, 2001). This approach, along with the approaches of other indigenous peoples, might give further specific pieces of advice to practitioners.

\section{A Theoretical and Practical Synthesis of the Three Articles for Pacific Rim Psychology}

The strengths of the three articles are obvious: they are written by senior figures in the field of cross-cultural psychology who have had substantial impact in their fields of expertise, both at the theoretical and practical level. The 'weaknesses' of the three, taken as a whole, are that they demonstrate that approaches to culture in psychology are still rather piecemeal, and that cross-cultural psychology as represented by these three articles does not present a united front vis-à-vis either mainstream psychology or a practice-based public. This, of course, is an opportunity for learning, which is what the authors actually signed up to facilitate.

In terms of cross-cultural psychology as a science, the lack of a canonical, or unified view of culture and psychology (at least in terms of references) is a disadvantage. Social cognition offers a paradigmatic view of the individual as a biological unit consisting of various cognitive and emotional modules that can be translated into interfaces with cognitive neuroscience. None of the three target articles would necessarily accept such a view, but they offer a pluralistic and possibly less unified account of alternatives. I would say that this opportunity for closer integration and harmonisation characterises the state of psychology as a whole: there are many dissenting views to the mainstream dominated by cognitive neuroscience, but each of these occupies a different margin and the sum total of their critiques does not at present amount to a viable, coherent or holistic alternative.

Each of the three target articles presents a different face of cross-cultural psychology and it is up to the reader to put them together in some way. Adrian Furnham's (2011) article focuses on the public face of cross-cultural psychology, using scientific research to meet a public need for advice on how to manage today's globally interconnected world of international education and international students. An indicator of his success at meeting this need is demonstrated in his prominence on a Google ${ }^{\mathrm{TM}}$ search. Furnham's highly visible presence on the internet positions him as an expert in the field who is able to draw on research-based expertise to solve practical problems. Thus, it is most informative that his approach to the problem of culture shock is very practical and centred around meeting everyday psychological needs (e.g., homesickness, making friends, providing counselling, etc).

John Berry's (2011) article is very theory-driven, providing a focused account of the theoretical foundation and empirical evidence for his theory of acculturation where an integrative approach provides the best outcomes for both individuals and society. Although he does not emphasise this point, Berry is a Canadian, and Canada is undisputed as the world's leading national advocate and practitioner of multiculturalism. Thus, Berry's research may be taken as a paradigmatic case where the passion and intellect of an eminent individual researcher resonate with a national agenda and a people's self-image. Berry (2011) argues that: 
in some societies (e.g., many countries in Europe, and in the United States) there is a common misunderstanding that multiculturalism means only the presence of many independent cultural communities in a society (only cultural maintenance), without their equitable participation and incorporation into a larger society. It is this erroneous view that has led some in Europe to declare that 'multiculturalism has failed'. However, it has not failed because it has not even been tried. (p. 99)

Finally, Marsella and Yamada (2011) represent a dissident view from the American mainstream academy of theory and practice, a cherished stance for cross-cultural psychology. In a classic issue of the Asian Journal of Social Psychology published in 1998, for example cultural, cross-cultural and indigenous psychologists espoused alternative approaches to culture in psychology, but were more united in their criticisms of the western mainstream. Unlike the other two articles that are more positive in their affirmations of best theory and/or practice, Marsella and Yamada (2011) consider the state of the art in western clinical psychology and psychiatric diagnosis to be severely deficient in theory and practice - being persistently culture-blind despite more than a quarter of a century of solid academic work chipping away at its ethnocentric ways. Similar to social constructionists from other fields, like feminism or qualitative methodology, the tone adopted by these authors is highly critical of the mainstream, suggesting that a fundamental, mutual accommodation of diversity is needed, in psychology as much as in wider society.

\section{What Lessons Should the Emerging Field of Pacific Rim Psychology Take Away From These Three Illustrations?}

The Pacific Rim is truly vast and in this vastness is a potential for incoherence. It would be hard for a fledgling journal like this one to claim much influence over East Asia and the western seaboard of the United States. But I like the editorial statement that 'the "hub" in the wheel' is the Hawaiian Islands and other Pacific Island Nations, and I do believe that a plausible mission statement for this journal should centre round such hub as its core.

For such a hub, issues of indigenous psychology would be very important. As Marsella and Yamada (2011) powerfully illustrated, indigenous Hawaiians have quite a distinctive psychology that is marginalised by the American mainstream. Similarly, in the South Pacific, the historical legacy of colonisation has left scars on the psyches of M ori in New Zealand (King, 2003; Walker, 1990) and Aboriginals in Australia (http://www.indigenouspsychology.com.au/). A 'post-' colonial society coupled with issues about indigeneity have produced political instability in Pacific Island Nations, most notably Fiji, but also others like Papua New Guinea and the Solomon Islands.

Given these difficult social issues, a focus on action would well serve such a core hub and its constituency.
Indigenous peoples are united by a postcolonial desire for effective action (Smith, 1999). As the journal's editorial description states, 'From climate change to disaster management and poverty reduction, the Pacific Rim region has its share of issues and potential solutions'. As Marsella and Yamada (2011) noted, power is not so easily dislodged from its privileged positions. I am on record (Liu, $\mathrm{Ng}$, Gastardo-Conaco, \& Wong, 2008) for stating that action research, involving a cyclical form of communication with planning, action, evaluation and feedback between researchers and others in sectors like government, business, NGOs and media is necessary to achieve effective action. In sociopolitical domains, pure knowledge is a necessary, but not sufficient basis for social action.

Such an action orientation would inevitably involve transcending disciplinary boundaries and then feeding these back into disciplinary theories and practices. The three target articles all point to different ways that psychology can transcend its disciplinary boundaries. Adrian Furnham's work shows that psychology can appeal to mass publics and that mass media can be a facilitator for the development of better science and a means for communicating useful science. Having a media-savvy champion like Furnham would surely be a great boon to Pacific Rim psychology. John Berry's work demonstrates that theory and governmental policy and practice can work like hand in glove, where the researcher's passions and intellect align fruitfully with a national agenda and a people's self-image. Having strong connections to government policy directions would again surely be a major asset to developing Pacific Rim psychology; but different parts of the rim would need to adapt to different sociopolitical and historical contingencies. Anthony Marsella and Ann Marie Yamada's work illustrates how a call for social justice and better quality research draw epistemology and indigenous psychology into institutional settings like hospitals, governments and clinics. Being grounded in clinical practice and having a good understanding of the workings of discourse and ideology is certainly a base from which cultural psychology is being developed for Aotearoa/New Zealand (see Durie, 2001; Hodgetts, in press; Sibley \& Liu, 2007; Tuffin, 2008; Rata, Liu, \& Hanke, 2008 for some recent examples).

Each of the three target articles points to a direction of engagement for Pacific Rim Psychology. The sum of their efforts may provide the broader basis for the vision of a hub and mission statement for psychology in this vast and often uncharted part of the world.

\section{References}

Berry, J. (2011). Intercultural relations and acculturation in the Pacific region. Journal of Pacific Rim Psychology, 4(2), 95-102.

Berry, J., Phinney, J.S., Sam, D.L., \& Vedder, P. (2006). Immigrant youth in cultural transition: Acculturation, iden- 
tity, and adaptation across national contexts. Mahwah, NJ: Lawrence Erlbaum.

Durie, M. (1997). Identity, nationhood and implications for practice in New Zealand. New Zealand Journal of Psychology, 26(2), 32-38.

Durie, M. (2001). Mauri Ora. Melbourne, Australia: Oxford University Press.

Furnham, A. (2011). Culture shock: Literature review, personal statement and relevance for the South Pacific, Journal of Pacific Rim Psychology, 4(2), 87-94.

Hodgetts, D. (in press). A M ori homeless woman. Ethnography, doi: 10.1177/1466138110393794.

King, M. (2003). The Penguin History of New Zealand. Auckland: Penguin Books.

Liu, J.H., Ng, S.H., Gastardo-Conaco, C., \& Wong, D.S.W.(2008). Action research: A missing component in the emergence of social and cross-cultural psychology as a fully inter-connected global enterprise. Social \& Personality Psychology Compass, Culture \& Diversity Section. Retrieved from http://www.blackwell-compass.com/subject/ socialpsychology/

Liu, J.H., \& Sibley, C.G. (2004). Attitudes and behavior in social space: Public good interventions based on shared representations and environmental influences. Journal of Environmental Psychology, 24(3), 373-384.
Marsella, A.J., \& Yamada, A.M. (2011). Culture and psychopathology: Foundations, issues, directions. Journal of Pacific Rim Psychology, 4(2), 103-115.

Oberg, K. 1960. Culture shock: adjustment to new cultural environments. Practical Anthropology 7, 177-182.

Rata, A., Liu, J.H., \& Hanke, K. (2008). Te ara hohou rongo (the path to peace): Maori conceptualisations of intergroup forgiveness. New Zealand Journal of Psychology, $37(2), 18-30$.

Sibley, C.S., \& Liu, J.H. (2007). New Zealand = bicultural? Implicit and explicit associations between ethnicity and nationhood in the New Zealand context. European Journal of Social Psychology, 37(6), 1222-1243.

Smith, L.T.H (1999). Decolonizing methodologies: Research and indigenous peoples. London: Zed Books.

Tuffin, K. (2008). Racist discourse in New Zealand and Australia: Reviewing the last 20 years. Social and Personality Psychology Compass, 10, 591-607.

Rudmin, F.W. (2006). Debate in science: The case of acculturation. AnthroGlobe Journal. Retrieved November 4, 2011, from http://www.anthroglobe.ca/docs/rudminf_acculturation_061204.pdf

Walker, R. (1990). Ka Whawhai Tonu Matou: Struggle without end. Auckland: Penguin.

Ward, C. (2001). The A, B, Cs of acculturation. In D. Masumoto (Ed.), The Handbook of Culture and Psychology (pp. 411-445). Oxford, UK: Oxford University Press. 